\title{
Transcriptional profiles of emasculated flowers of black locust (Robinia pseudoacacia) determined using the cDNA-AFLP technique
}

\author{
J.X. Wang ${ }^{1 *}$, P. Sun ${ }^{2 *}$, C.Q. Yuan ${ }^{1}$, L. Dai ${ }^{1}$, Y. Zhang ${ }^{1}$, B. Wu ${ }^{1}$, C. Long ${ }^{1}$, \\ Y.H. Sun ${ }^{1}$ and Y. Li ${ }^{1}$ \\ ${ }^{1}$ National Engineering Laboratory for Tree Breeding, \\ Key Laboratory of Genetics and Breeding in Forest Trees and Ornamental Plants, \\ Ministry of Education, College of Biological Sciences and Technology, \\ Beijing Forestry University, Beijing, China \\ ${ }^{2}$ Non-Timber Forestry Research and Development Center, \\ Chinese Academy of Forestry, Zhengzhou, China \\ *These authors contributed equally to this study. \\ Corresponding authors: Y.H. Sun / Y. Li \\ E-mail: sunyuhan@bjfu.edu.cn / yunli@bjfu.edu.cn \\ Genet. Mol. Res. 14 (4): 15822-15838 (2015) \\ Received July 17, 2015 \\ Accepted October 14, 2015 \\ Published December 1, 2015 \\ DOI http://dx.doi.org/10.4238/2015.December.1.34
}

ABSTRACT. Black locust (Robinia pseudoacacia) is a tree in the subfamily Faboideae, native to North America, that has been naturalized and widely planted in temperate Europe and Asia. Black locust has important ecological and economic value, but its quality needs improvement. Hybridization programs are important for black locust breeding, but the low rate of fruit set after controlled pollination limits both its breeding and that of other monoclinous plant species that share this problem. In this study, we investigated gene expression in emasculated black locust flowers using the cDNA-amplified fragment length polymorphism technique to determine why the rate of fruit set is low after controlled pollination. Flowers that were emasculated after being frozen in liquid nitrogen were used as controls. Changes in the flower transcriptome were more dramatic at $5 \mathrm{~h}$ after emasculation than at $48 \mathrm{~h}$. Injury caused by emasculation decreased the expression levels of genes associated with metabolism, growth regulation, signal transduction, and photosynthesis, and it increased the 
expression of genes related to stress-response metabolism, signal transduction, and promotion of senescence. The changes in the expression levels of these genes had negative effects on sugar metabolism, protein metabolism, lipid metabolism, energy metabolism, matter transport, signal transduction, osmotic regulation, $\mathrm{pH}$ regulation, and photosynthesis. Thus, emasculation accelerated flower senescence, resulting in low fruit set.

Key words: Black locust; Robinia pseudoacacia; cDNA-AFLP; Emasculation

\section{INTRODUCTION}

Black locust (Robinia pseudoacacia) is a monoclinous plant in the subfamily Faboideae that is native to North America, and it is widely planted and naturalized elsewhere in temperate Europe and Asia. Black locust has considerable ecological and economic value (Keeler, 1900; Yuan et al., 2013), but there are many problems that restrict cultivation of the tree. The breeding method most commonly used for black locust depends mainly on genotypic introduction and selection, and it has made significant contributions to breeding programs. However, the availability of desirable traits for introduction is limited, and genotypic selection is an uncertain basis for breeding programs. Space flight mutation-breeding technology has been applied to black locust. However, the main problems of this method are that the beneficial mutation frequency is still low, and the direction and character of the variation is difficult to control (Yuan et al., 2010). Breeding programs based on controlled pollination provide an important alternative approach for breeding black locust. However, low fruit set rates after controlled pollination result in insufficient numbers of offspring for progeny selection, and most flowers that result from artificial hybridization abscise approximately 1 week after artificial pollination. The low rate of fruit set associated with the use of artificial hybridization is shared with other monoclinous plant species such as sweet cherry (Hedhly et al., 2009), plum (Guerra et al., 2010), amarelle, and other plants with hermaphroditic flowers (Guerra et al., 2010). This phenomenon has presented a major impediment to the artificial cross breeding of black locust and other monoclinous plants.

The cDNA-amplified fragment length polymorphism (AFLP) technique is an efficient and simple mRNA fingerprinting method for the isolation of differentially expressed genes (Bachem, 1996). This technique is based on the selective PCR amplification of restriction fragments produced from a restriction digest of total genomic DNA (Vos et al., 1995). This is a robust and high-throughput tool for analyzing genome-wide expression and for gene discovery where prior knowledge of gene sequences is not a prerequisite. The high sensitivity of this method makes the identification of rare transcripts possible (Fukumura et al., 2003). The cDNA-AFLP technique has been improved to avoid the possibility of multiple-transcript-derived fragments (TDFs) arising from a single gene or cDNA(Breyne et al., 2003).

In this study, we used the cDNA-AFLP technique to investigate the effect of emasculation damage on gene expression to obtain a more comprehensive understanding of the effects of damage caused by emasculation on ageing and the rate of seed set after artificial hybridization.

\section{MATERIAL AND METHODS}

\section{Plant material}

Flowers were collected from an adult black locust tree exhibiting normal growth and 
development at the Mijiabao Forestry Station in Beijing, Yanqing, China. Pollen was collected from ripe flowers, stored in glass bottles containing silica gel at $4^{\circ} \mathrm{C}$, and used within 3 days after collection to avoid viability loss. To emasculate flowers, we removed partial petals and entire stamens 1 day prior to anthesis to avoid contamination from self-pollen, and the flowers were placed in paper bags (Figure 1). After removal from the bags at $24 \mathrm{~h}$ after emasculation, the emasculated flowers were pollinated artificially with prepared pollen, and the flowers were returned to bags for 7 days.

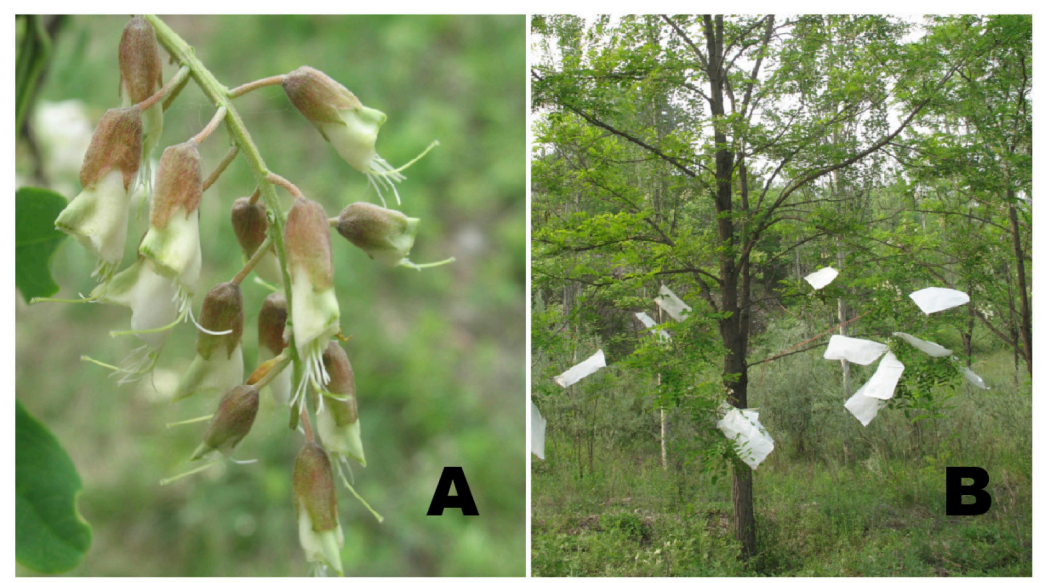

Figure 1. Treatment of black locust flowers by $(\mathbf{A})$ emasculation and $(\mathbf{B})$ bagging.

Unemasculated control flowers were placed in paper bags 1 day prior to anthesis, and were removed from the bags immediately before beginning artificial pollination. After pollination, the flowers were bagged for 7 days. Therefore, differences between control and emasculated flowers were due only to the effects of emasculation (Sun et al., 2013).

We collected the emasculated and control flowers at 5 and $48 \mathrm{~h}$ after emasculation. To ensure consistency in the processing of materials, the control flowers were first frozen in liquid nitrogen. The frozen corolla and stamens were treated identically to those of emasculated flowers so that differences between the treatment and control would be due only to physiological responses to emasculation and not to differences in sample processing. All samples were frozen immediately in liquid nitrogen and transported to the laboratory, where they were stored at $-80^{\circ} \mathrm{C}$ until use for CDNA-AFLP analysis.

\section{Total RNA extraction, mRNA isolation, and cDNA synthesis}

Total RNA was extracted from 100-g tissue samples using an Aidlab EASYspin Plus Rapid Rlant RNA Extraction Kit (Aidlab Biotechnologies Co, Ltd., China). RNA quality and quantity were determined using a NanoDrop1000 spectrophotometer (NanoDrop Technologies, USA). RNA samples with $A_{260} / A_{280}$ ratios between 1.9 and 2.1 and $A_{260} / A_{230}$ ratios between 2.0 and 2.5 were assessed for RNA integrity by electrophoresis on $1.5 \%$ agarose gels alongside an RNA ladder (Invitrogen, Carlsbad, CA, USA). RNAs that met the quality criteria were used to synthesize cDNA. PolyA mRNA was isolated from total RNA (0.5-1.0 g) using a PolyATract mRNA isolation system (Promega, Madison, WI, USA), according to the manufacturer instructions. For cDNA synthesis, mRNAs from the collected tissues were pooled and used for first-strand cDNA synthesis, followed by second-strand synthesis, using a SuperScript double-stranded cDNA synthesis kit (Invitrogen) per the manufacture instructions with custom synthesized poly-d[T]25 oligonucleotides (Alpha DNA, Canada). 


\section{cDNA-AFLP analysis}

Approximately $500 \mathrm{ng}$ double-stranded cDNA were used for standard AFLP template production, according to the method of Vos et al. (1995). The cDNA was digested using Msel and EcoRI restriction enzymes (New England Biolabs, Inc., USA). The digested products were ligated to adapters using the following primer sequences: Eup, 5'-CTCGTAGACTGCGTACC-3'; Edown, 5'-AATTGGTACGCAGTCTAC-3'; Mup, 5'-GACGATGAGTCCTGAG-3'; and Mdown, 5'-TACTCAGGACTCAT-3'.

Equal amounts of preamplified products were amplified using two primers with selective nucleotides at their 3'-ends: E0, 5'-GACTGCGTACCAATTCA-3' and M0, 5'-GATGAGTCCTGAGTAA C-3'. A total of 51 primer combinations were tested. Four microliters of the AFLP products were heat-denatured and resolved on a $6 \%$ denaturing polyacrylamide sequencing gel containing $0.5 \mathrm{X}$ TBE electrophoresis buffer using a Sequi-Gen system (Bio-Rad Laboratories, Hercules, CA, USA). The gels were silver-stained using a Silver Sequence kit (Promega) according to the manufacturer instructions. All reactions for restriction digestion, adapter ligation, preamplification, and selective amplification were performed according to procedures described by Subudhi (1998).

Gel bands corresponding to polymorphic fragments were excised from the gel with a scalpel after wetting the bands with $6 \mu \mathrm{L} \mathrm{ddH}_{2} \mathrm{O}$. The gel bands were placed in $20 \mu \mathrm{L} \mathrm{ddH}_{2} \mathrm{O}$, incubated at $95^{\circ} \mathrm{C}$ in a water bath for $10 \mathrm{~min}$, and centrifuged at $12,000 \mathrm{rpm}$ for $5 \mathrm{~min}$, and the supernatants were recovered as templates. Reamplification of the fragments was performed using the same selective amplification primers used for preamplification. Reactions contained $8.5 \mu \mathrm{L}$ $\mathrm{ddH}_{2} \mathrm{O}, 2 \mu \mathrm{L}$ E0 (selective amplification primer, $10 \mathrm{pM} / \mu \mathrm{L}$ ) or M0 (selective amplification primer, 10 $\mathrm{pM} / \mu \mathrm{L}$ ) primers, $22.5 \mu \mathrm{L} 2 \mathrm{X}$ taq Mix (TaKaRa, Dalian, China), and $10 \mu \mathrm{L}$ enzyme ligation product. PCR conditions used in reamplification were the same as those used for the preamplification step.

\section{Sequencing of fragments and gene ontology annotation}

Reamplified PCR products $(5 \mu \mathrm{L})$ were resolved on $2 \%$ agarose gels. Those that produced clear, single bands were submitted for sequencing (Biomed Corporation, China). The sequences were analyzed using the BLASTx software (http://blast.ncbi.nlm.nih.gov/blast/ Blast.cgi?PROGRAM=blastX\&PAGE_TYPE=BlastSearch\&LINK_LOC=blasthome) to identify homologous proteins in the GenBank database at the National Center for Biotechnology Information (NCBI). For sequences with low homology to protein sequences, the BLASTn software (http:// blast.ncbi.nlm.nih.gov/blast/Blast.cgi?PROGRAM=blastn\&PAGE_TYPE=BlastSearch\&LINK_ LOC=blasthome) was used to identify homologous gene fragments in the GenBank database at NCBI. The Uniprot Protein (UniProtKB, http://www.uniprot.org/) database was searched to further characterize the potential functions of the homologous proteins and gene fragments.

\section{Verification of expression using real-time quantitative PCR (RT-qPCR)}

RT-qPCR was performed using a 7500 Fast Real-Time PCR machine (Applied Biosystems, CA, USA) and a SYBR Ex Taq Kit (TaKaRa). The PCR program included an initial denaturation step at $95^{\circ} \mathrm{C}$ for $3 \mathrm{~min} ; 40$ cycles of $30 \mathrm{~s}$ at $95^{\circ} \mathrm{C}, 30 \mathrm{~s}$ at $60^{\circ} \mathrm{C}, 30 \mathrm{~s}$ at $72^{\circ} \mathrm{C}$, and a final melting curve of $70^{\circ}-95^{\circ} \mathrm{C}$. PCRs were prepared in $20-\mu \mathrm{L}$ volumes containing $2 \mu \mathrm{L} 10$-fold-diluted synthesized cDNA, $10 \mu \mathrm{L} 2 X$ SYBR Premix Ex Taq, $0.4 \mu \mathrm{L} 10 \mu \mathrm{M}$ primer, $0.5 \mu \mathrm{L}$ 50X ROX reference dye, and $6.9 \mu \mathrm{L}$ $\mathrm{ddH}_{2} \mathrm{O}$. The melting curve was used to verify the specificity of amplified fragments. All reactions were 
performed in triplicate for technical replication, with the biological replication of three plants per test. Expression levels were standardized using ACTIN gene expression, and the RT-qPCR data were analyzed using ANOVA. The primer pairs used for RT-qPCR are listed in Table 1.

Table 1. Primer pairs used for RT-PCR.

\begin{tabular}{lllr}
\hline Gene name & Forward primer & Reverse primer & PCR efficiency (\%) \\
\hline T3 & AAGAGCCATCGCAGGTAT & TTGGGATTGTTCAAGGGA & 99.1 \\
T5 & CTTCTATCCTGGTTCTCA & GGAAGTTTCAGTTTCCTA & 101.6 \\
T12 & GTAAGTGGCTGGGTTGCG & GAAGTGGGTGGGTTGAG & 99.3 \\
T13 & TGAAGCCATTGGTTGAT & 101.1 \\
T18 & AAGGGCTCCAATTTCTC & CAAGTGGGACATAAGTTCA & 99.5 \\
T25 & GAGCATCATCAAAGGGAC & GGTTACAGGGAGTGTTCTA & 98.8 \\
T90 & ATTATTCCGTGTCTTTCG & GTCTTCAGAACTGGAGGG & 102.4 \\
T96 & ACAGGACAAACGGCATAA & CTCCGATGGTAGATTTGG & 102.3 \\
Actin & TGGGACTCTGGTGTAAGC & GATGGCTGGAACAGAACTT & 99.2 \\
\hline
\end{tabular}

\section{RESULTS}

\section{Sequence analysis}

We used 80 pairs of selective amplification primers to identify differences in gene expression between emasculated and control flowers at 5 and $48 \mathrm{~h}$ time points after emasculation. Approximately 3000 DNA fragments were amplified (Figure 2), 100 of which were TDFs. The sequenced products of reamplification included those that resolved as clear, single bands using agarose gel electrophoresis and those that exhibited band sizes that were the same on a $6 \%$ polyacrylamide gel. Seventy-three fragments were sequenced successfully. Both BLASTn and BLASTx softwares were used to identify homologous protein and gene sequences in the GenBank database, and functional identifications were refined by searching the UniProtKB database. The results of the homology analysis are presented in Table 2.

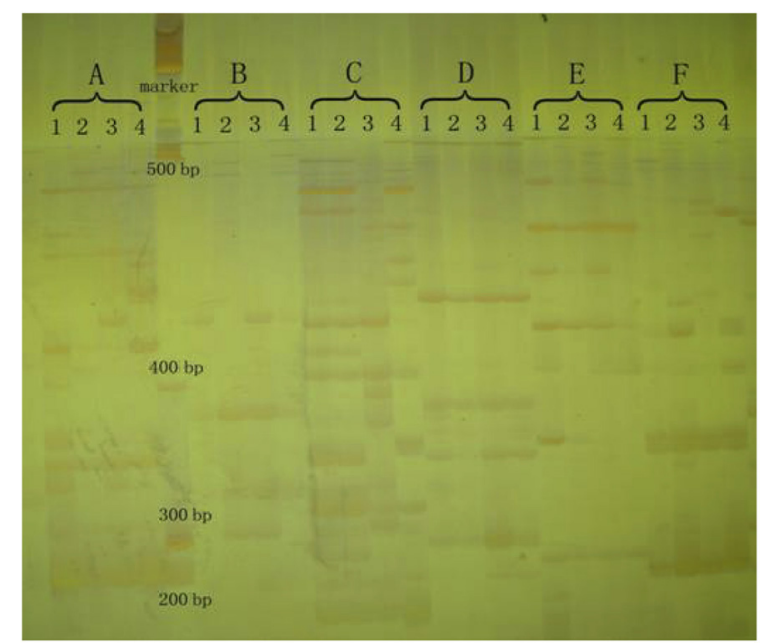

Figure 2. Electrophoretogram of CDNA-AFLP. A, B, C, D, E, F indicate different primer pairs. Lane 1: control flowers at $5 \mathrm{~h}$ after emasculation. Lane 2: flowers at $5 \mathrm{~h}$ after emasculation. Lane 3: control flowers at $48 \mathrm{~h}$ after emasculation. Lane 4: flowers $48 \mathrm{~h}$ after emasculation. 
Transcriptional profiles of black locust emasculated flowers

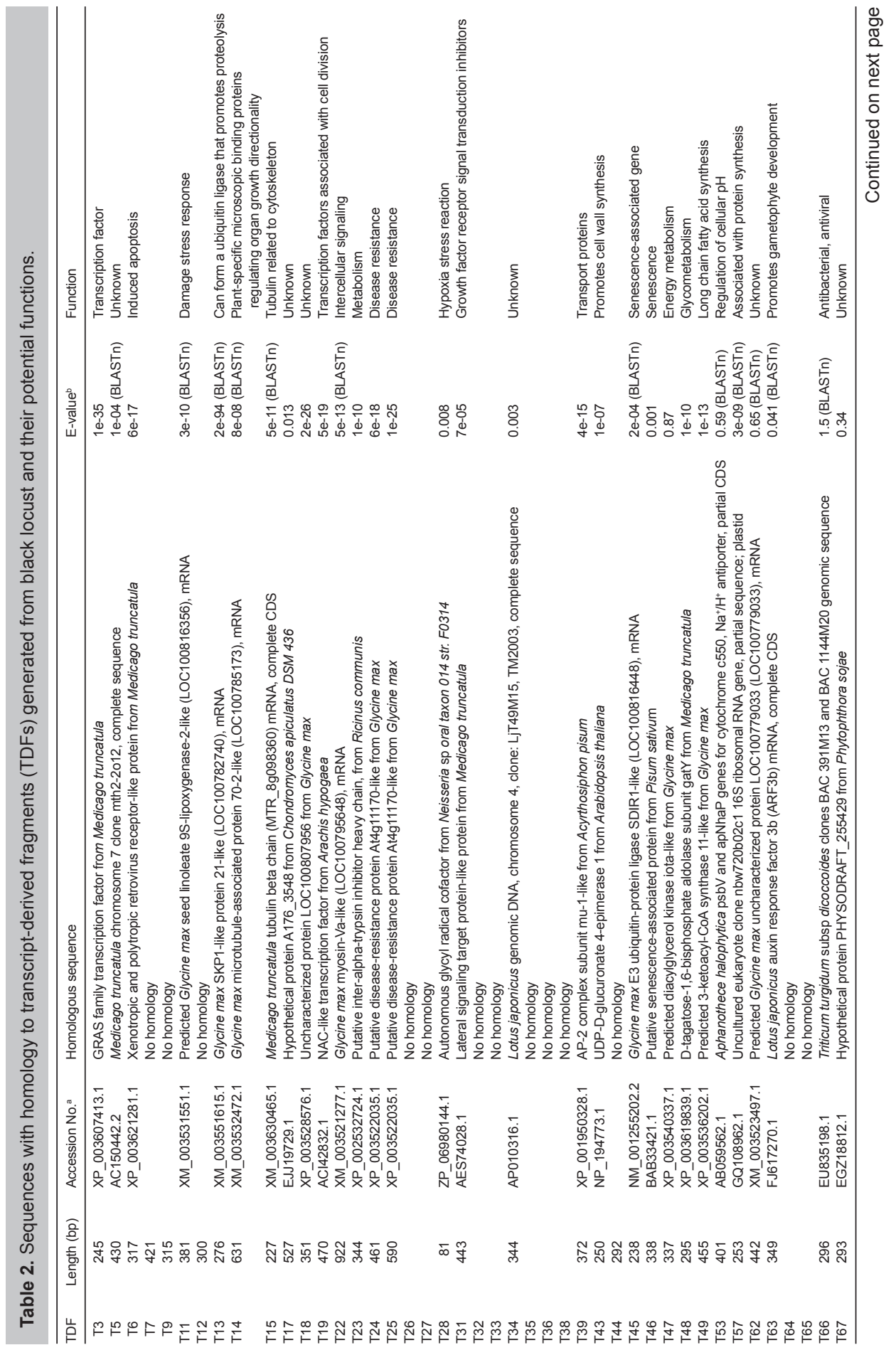




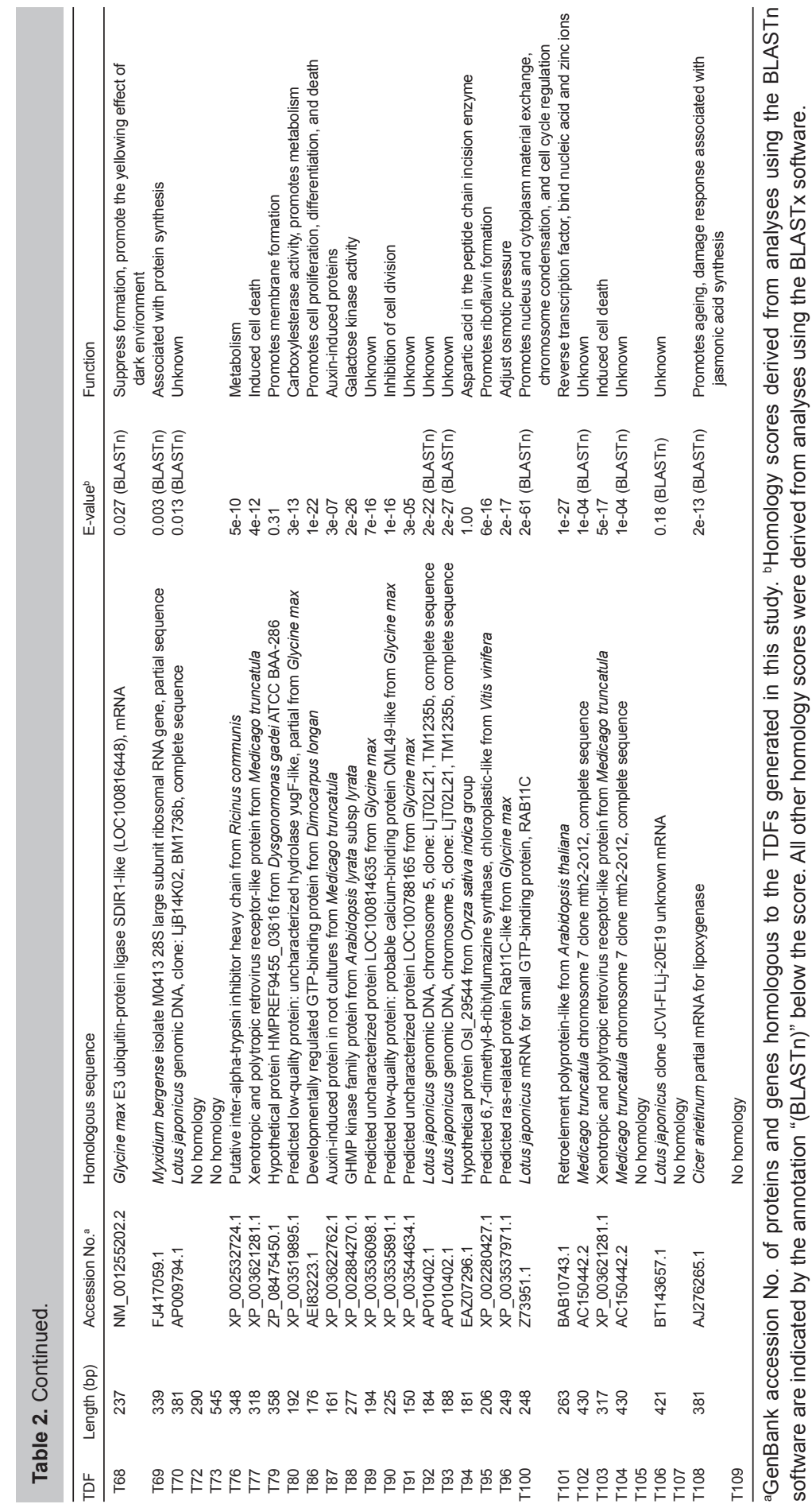




\section{Expression analysis and functional classification of TDFs}

The differential expression characteristics of the TDFs are summarized in Table 3. According to Bhalerao et al. (2003), we divided the TDFs into eight categories based on the functions of their homologous sequences in GenBank: cell metabolism, ageing-related (senescence), stress responses, signal transduction and growth regulation, transcription factor, photosynthesis, unknown function, and no homology. All of the categories containing TDFs are shown in Table 4.

\section{TDFs related to cell metabolism}

Of the sequenced TDFs, $19.2 \%$ had functions related to cell metabolism, indicating the marked effect of emasculation on cell metabolism. The expression levels of some genes with functions related to cell metabolism were reduced by emasculation. The TDF designated T48 was homologous to aldolase, which catalyzes the catabolism of galactitol, N-acetyl-galactosamine, and d-galactosamine, and it plays an important role in glucose metabolism (Brinkkoetter et al., 2002). T48 was expressed highly in control flowers at 5 and $48 \mathrm{~h}$, but its expression was reduced in emasculated flowers at both time points.

The homolog of T49 maintains the length of very-long-chain fatty acids between 26 and 30 carbon atoms. Very-long-chain fatty acids are hydrophobic, high-molecular weight polymers that prevent plant leaves from becoming too dry, providing a suitable environment for pollen (Trenkamp et al., 2004). The T49 homolog also improves the performance of the cuticle of epithelial cells by catalyzing lipid synthesis (Pruitt et al., 2000). In addition, the T49 homolog prevents abnormal pollen hydration and germination, promotes ovule formation, and regulates epithelial cell growth during pistil morphogenesis (Lolle and Cheung, 1993). These results indicated that T49 is involved in pollen and ovule development. T49 was expressed at high levels only in the control flowers at $5 \mathrm{~h}$, and its expression was barely detectable in emasculated flowers at $5 \mathrm{~h}$. Thus, emasculation had a negative effect on the normal development of male and female reproductive organs.

The homolog of T79 promotes the insertion of intrinsic proteins into the cell membrane, and it plays a role in intrinsic protein folding and complex formation. It also promotes the synthesis and translocation of lipoprotein in the cell membrane, suggesting that T79 may play important roles in cell membrane function. T79 was highly expressed in the control flowers at $48 \mathrm{~h}$, but showed little expression in the emasculated flowers at $48 \mathrm{~h}$, which suggests that emasculation may affect cytomembrane function.

The homolog of T80 was a carboxyl esterase gene, the product of which catalyzes the hydrolysis of esters, sulfate esters, and amides. The homolog of T94 has endopeptidase activity, and is involved in protein metabolic processes (Yu et al., 2005). The homolog of T95 promotes the synthesis of riboflavin, which is involved in in vivo biological oxidation, energy metabolism, and metabolism associated with cell growth. T80, T94, and T95 were all expressed highly in the control flowers at $5 \mathrm{~h}$, but their expression was almost undetectable in the emasculated flowers, indicating that emasculation had a negative impact on the material and energy metabolism of cells and on pollen and ovule growth. These effects may explain the premature senescence and abscission and the low fruit set rate of emasculated flowers. T57 was homologous to a $16 \mathrm{~S}$ ribosomal ribonucleic acid (rRNA) gene, and it was expressed in the control flowers at $5 \mathrm{~h}$; however, it showed little expression in the emasculated flowers. 
Table 3. Expression characteristics of transcript-derived fragments (TDFs).

\begin{tabular}{|c|c|c|c|c|}
\hline TDF & Control $5 \mathrm{~h}$ & Emasculation $5 \mathrm{~h}$ & Control $48 \mathrm{~h}$ & Emasculation $48 \mathrm{~h}$ \\
\hline T3 & & - & & - \\
\hline $\begin{array}{l}\text { T5 } \\
\text { T6 }\end{array}$ & $\begin{array}{l}\circ \\
\circ\end{array}$ & 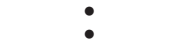 & . & . \\
\hline $\mathrm{T} 7$ & $\circ$ & - & 0 & - \\
\hline T9 & $\circ$ & - & $\circ$ & - \\
\hline T11 & & - & & \\
\hline T12 & - & - & & \\
\hline T13 & - & $\circ$ & - & $\circ$ \\
\hline T14 & & - & $\circ$ & $\circ$ \\
\hline T15 & & - & & \\
\hline T17 & & - & & \\
\hline T18 & & - & & - \\
\hline T19 & & - & & - \\
\hline T22 & & - & & - \\
\hline T23 & $\circ$ & - & & \\
\hline T24 & $\circ$ & - & & \\
\hline T25 & $\circ$ & - & & \\
\hline T26 & & - & & \\
\hline T27 & - & & - & \\
\hline $\begin{array}{l}\text { T28 } \\
\text { T31 }\end{array}$ & & : & & \\
\hline T32 & - & $\bullet$ & & \\
\hline T33 & - & ○ & - & $\circ$ \\
\hline T34 & - & & & \\
\hline T35 & & $\circ$ & & $\circ$ \\
\hline T36 & & $\circ$ & & \\
\hline T38 & & - & & \\
\hline T39 & - & 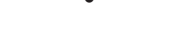 & - & \\
\hline T43 & & $\circ$ & & \\
\hline T44 & - & ० & - & \\
\hline T45 & & & & - \\
\hline T46 & & - & & \\
\hline T47 & & - & & \\
\hline T48 & - & $\circ$ & - & $\circ$ \\
\hline T49 & - & & & \\
\hline T53 & - & & & \\
\hline T57 & $\circ$ & & & \\
\hline T62 & & - & & - \\
\hline T63 & - & & & \\
\hline T64 & & - & & \\
\hline T65 & & - & & - \\
\hline T66 & $\circ$ & - & & \\
\hline T67 & - & 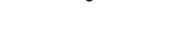 & - & \\
\hline T68 & & & & $\circ$ \\
\hline T69 & $\circ$ & - & & \\
\hline T70 & & & - & \\
\hline $\mathrm{T} 72$ & - & $\circ$ & $\circ$ & \\
\hline $\mathrm{T} 73$ & $\circ$ & $\circ$ & - & \\
\hline T76 & $\circ$ & - & & \\
\hline $\mathrm{T} 77$ & & - & & - \\
\hline T79 & & & - & \\
\hline T80 & - & & 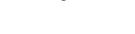 & \\
\hline T86 & & & - & \\
\hline T87 & & - & & \\
\hline T88 & & & & - \\
\hline T89 & & & & - \\
\hline T90 & - & - & & \\
\hline T91 & & - & & \\
\hline T92 & $\circ$ & $\circ$ & $\circ$ & • \\
\hline T93 & & & & • \\
\hline T94 & $\bullet$ & & & \\
\hline T95 & • & & & \\
\hline T96 & • & & • & \\
\hline T100 & & & • & \\
\hline T101 & & • & 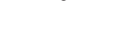 & \\
\hline T102 & 0 & • & & \\
\hline T103 & 0 & $\bullet$ & $\circ$ & $\bullet$ \\
\hline T104 & 0 & $\bullet$ & & \\
\hline T105 & $\circ$ & • & & \\
\hline T106 & $\circ$ & • & $\circ$ & • \\
\hline T107 & 0 & • & & \\
\hline T108 & & • & & \\
\hline T109 & $\bullet$ & • & & \\
\hline
\end{tabular}

-cDNA band on a gel was distinct, and the gene expression level was high. ocDNA band on a gel was indistinct, and the gene expression level was low. The absence of $\bullet$ or $\circ$ indicates that expression was not detected. 
Table 4. Functional classification of differentially expressed genes induced by emasculation injury.

\begin{tabular}{llrr}
\hline TDF function & TDF ID & TDF quantity & Percentage (\%) \\
\hline Cell metabolism & T15, T23, T43, T47, T48, T49, T57, T69, T76, T79, T80, T88, T94, T95 & 14 & 7 \\
Ageing-related & T6, T13, T45, T46, T68, T77, T103 & 6 & 19.2 \\
Stress response & T11, T24, T25, T28, T66, T108 & 10 & 9.6 \\
Signal transduction and & T14, T22, T31, T39, T63, T86, T87, T90, T96, T100 & 3 & 13 \\
$\quad$ growth regulation & & 13.7 \\
Transcription factor & T3, T19, T101 & 14 & 4.1 \\
Photosynthesis & T53 & T5, T17, T18, T34, T62, T67, T70, T89, T91, T92, T93, T102, T104, T106, & 1.4 \\
Unknown function & T7, T9, T12, T26, T27, T32, T33, T35, T36, T38, T44, T64, T65, T72, T73, & 18 & 20.5 \\
No homology & T105, T107, T109 & 73 & 23.3 \\
& & &
\end{tabular}

TDF = transcript-derived fragments.

Emasculation promoted the expression of multiple genes related to cellular metabolism. T15 was homologous to tubulin, and it was expressed highly at $5 \mathrm{~h}$ after emasculation. The homolog to both T23 and T76 regulates the localization, synthesis, and decomposition of hyaluronan, which is involved in water retention, and it also plays important roles in the maintenance of normal biological cell function. Emasculation increased the expression of both T23 and T76. A T43 homolog catalyzes the synthesis of negatively charged monosaccharides, which are essential components of pectin (Usadel et al., 2004), and its expression also increased at $5 \mathrm{~h}$ after emasculation. A T47 homolog promotes the synthesis of ATP, consistent with a role in cellular metabolism, and it was highly expressed at $5 \mathrm{~h}$ after emasculation. T88 is homologous to galactokinase, which catalyzes the dephosphorylation of ATP, and its expression increased dramatically in flowers at $48 \mathrm{~h}$ after emasculation. These results indicated that responses to emasculation in flower organs include increased water retention, increased cell wall synthesis, and increased energy metabolism. These responses reduce the negative effects of injury from emasculation on flower development. T69 was homologous to a $28 \mathrm{~S}$ large subunit rRNA gene involved in protein synthesis, and its expression increased at $5 \mathrm{~h}$ after emasculation relative to the control flowers.

\section{TDFs related to senescence}

TDFs related to senescence accounted for $9.6 \%$ of all sequenced TDFs. T6, T77, and T103, which promote Xpr1 protein expression, were homologous. Xpr1 induces apoptosis after binding to heterophil (Bamunusinghe et al., 2013) or polytropic retrovirus in humans. This result suggested that T6 induces senescence and apoptosis of black locust flower organs after retrovirus infection. T6, T77, and T103 expression in flowers was higher at 5 and $48 \mathrm{~h}$ after emasculation compared to the control flowers. T45 and T68 were both homologous to ubiquitin ligase, which promotes protein ubiquitination and subsequent hydrolysis into small polypeptide fragments and amino acids. T45 and T68 were homologous, and the expression of both increased in flowers at $48 \mathrm{~h}$ after emasculation. The function of a T46 homolog was related to the decomposition of metaprotein in chloroplasts, and it was expressed highly at $5 \mathrm{~h}$ after emasculation.

Because the Arabidopsis-SKP1-like (ASK) gene, homologous to T13, is a substrate of ubiquitin ligase that may promote protein hydrolysis, we classified T13 as being functionally related to senescence. In the ASK1 mutant of Arabidopsis thaliana, vegetative and reproductive 
growth, leaf area, cell number, corolla number, and anther number were all markedly decreased. ASK increases plant sensitivity to auxin (Maldonado-Calderon et al., 2012), and it affects the normal separation of alleles in the microsporocyte during the post-meiotic phase, thus causing male sterility in Arabidopsis (Yang et al., 1999). Furthermore, ASK plays important roles in corolla and stamen development, and the absence of ASK has adverse effects on embryo formation and postembryonic development (Liu et al., 2004). Based on these characteristics, T13 is likely to be involved in protein hydrolysis, and it is classified as functionally related to senescence. However, the protein hydrolyzed by ASK functions as a gene repressor that promotes growth and development, so T13 may indirectly promote plant growth and development. Relative to the control flowers, T13 expression decreased markedly at both 5 and $48 \mathrm{~h}$ after emasculation, indicating that emasculation had a negative effect on flower development, embryo formation, and development during the postembryonic period.

\section{TDFs related to stress responses}

T11 and T108 were both homologous to a gene encoding a lipoxygenase inducer. This type of gene plays roles in insect resistance, induction of cell senescence, and responses to mechanical injury to cells (Coffa et al., 2005). T11 was expressed highly in flowers at $5 \mathrm{~h}$ after emasculation, and T108 expression increased at $48 \mathrm{~h}$ after emasculation. Both T24 and T25 were homologous to a putative disease-resistance protein. The function of the T28 homolog was related to the resistance response of alkaline anaerobic bacteria to oxygen (Wagner et al., 2001). A gene homologous to T66 showed a strong antibacterial effect in vitro (Shi et al., 2014). T24, T25, T28, and T66 all exhibited little or no expression at $5 \mathrm{~h}$ in the control flowers, but their expression levels were markedly increased in the emasculated flowers.

\section{TDFs related to signal transduction and growth regulation}

Genes functionally related to signal transduction and growth regulation accounted for $16.4 \%$ of the sequenced TDFs. The expression of many of the TDFs in these categories decreased after emasculation. T39 was expressed highly at 5 and $48 \mathrm{~h}$ in the control flowers, but showed very little expression in the emasculated flowers. The T39 homolog, a component of the adaptor protein complex 2 (AP-2), belongs to the cohesion protein complex. AP promotes the formation of vesicles encapsulated by clathrin and participates in the identification of target proteins to be transported (Kelly et al., 2008). AP also promotes the endocytosis of vesicles containing target proteins. Endocytosis of vesicles and the target proteins requires the participation of AP (Owen et al., 2004). The T39 homolog also plays important roles in intracellular transport. The Arabidopsis homologs of T63 belong to the BT protein family, which includes auxin-response proteins that play important roles in male and female gametophyte development in Arabidopsis (Robert et al., 2009). BT also reduces the inhibition of Arabidopsis seed germination by abscisic acid and carbohydrates and increases the plant response to auxin (Mandadi et al., 2009). T63 was highly expressed in control flowers at $5 \mathrm{~h}$, but showed very little expression in the emasculated flowers. T86 and T100 homologs are GTP-binding proteins necessary for the transport of protein and RNA from the nucleus to the cytoplasm. T86 expression decreased at $48 \mathrm{~h}$ in the emasculated flowers, and T100 was highly expressed only in control flowers at $48 \mathrm{~h}$. T96 was homologous to the Rab11 gene, which is important in the control of cellular osmotic pressure (Harris et al., 
2001). T96 was expressed highly in control flowers at 5 and 48 h, but expressed at low levels in the emasculated flowers.

The expression of many of the TDFs that were functionally related to signal transduction and growth regulation increased after emasculation. T14 was homologous to a gene encoding a plant microtubule binding protein, which guides the growth direction of cortex microtubules in some organs (Yao et al., 2008). T14 expression increased at $5 \mathrm{~h}$ in the emasculated flowers. T22 was homologous to an anticoagulation protein, which promotes the recycling of membrane receptor proteins and plays an important role in the regulation of intercellular signal transduction (Heazlewood et al., 2004). T22 was highly expressed at 5 and $48 \mathrm{~h}$ after emasculation, but was expressed at very low levels in the control flowers. The T31 homolog inhibits signal transduction mediated by the epidermal growth factor receptor (Yoo et al., 2004). T31 expression was increased markedly at $5 \mathrm{~h}$ in the emasculated flowers relative to the control flowers. T87 was homologous to an auxin-induced protein that may play roles in the connection between the cell wall and the cytoplasm (Neuteboom et al., 1999). T87 was highly expressed only in flowers $5 \mathrm{~h}$ after emasculation. T90 was homologous to a calcium binding protein that promotes cell division and trichome formation (Reddy et al., 2004). T90 was highly expressed at $5 \mathrm{~h}$ in both the control flowers and emasculated flowers, but exhibited very little expression at $48 \mathrm{~h}$ in either.

\section{TDFs related to transcription factors}

Three TDFs were homologous to transcription factor genes. T3 was homologous to a transcription factor belonging to the GRAS family, the function of which remains to be determined. T19 was homologous to an NAC transcription factor that promotes cell proliferation, differentiation, and division (Smyczynski et al., 2006). T3 and T19 were both expressed highly at 5 and $48 \mathrm{~h}$ after emasculation, but showed little expression in the control flowers. T101 was homologous to a retroelement that might bind nucleic acid and zinc ions. T101 was expressed highly at $5 \mathrm{~h}$ after emasculation.

\section{TDFs related to photosynthesis}

T53 was homologous to a cytochrome $\mathrm{C}$ gene or a gene involved in the transfer of sodium and hydrogen ions. Cytochrome $\mathrm{C}$ maintains photosystem stability and promotes the release of oxygen. Sodium and hydrogen ion transfer regulates intracellular $\mathrm{pH}$ (Taglicht et al., 1991), but more data are needed to clarify the function of T53. T53 was highly expressed in the control flowers at $5 \mathrm{~h}$, but exhibited little expression in the emasculated flowers.

\section{RT-qPCR analysis}

The expression levels of eight TDFs, representing genes that exhibited various expression patterns in response to emasculation damage, were determined by RT-qPCR. The black locust ACTIN gene was used as an internal control to which transcript abundance was normalized. The transcript fold-ratios determined by RT-qPCR were similar to those determined by cDNA-AFLP for all eight TDFs, confirming the reliability of the cDNA-AFLP technique (Figure 3). 
T3

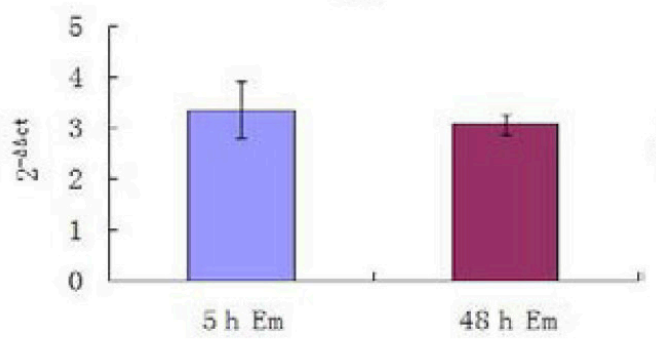

T12

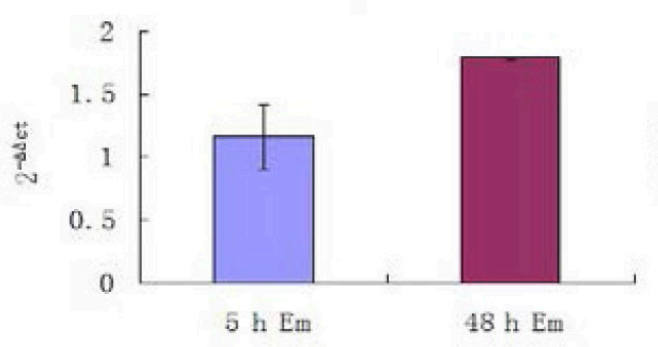

T18

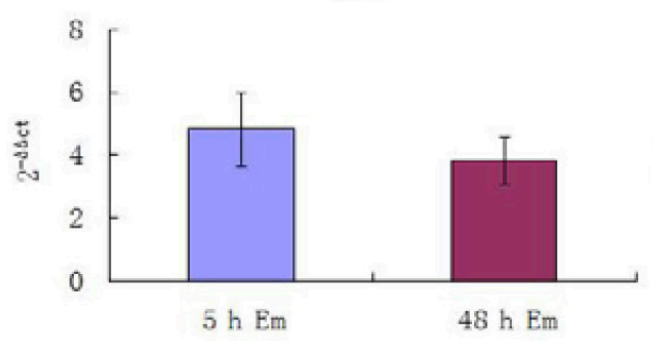

T90

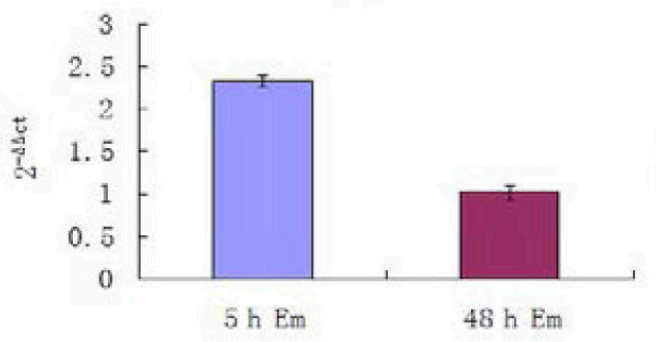

T5

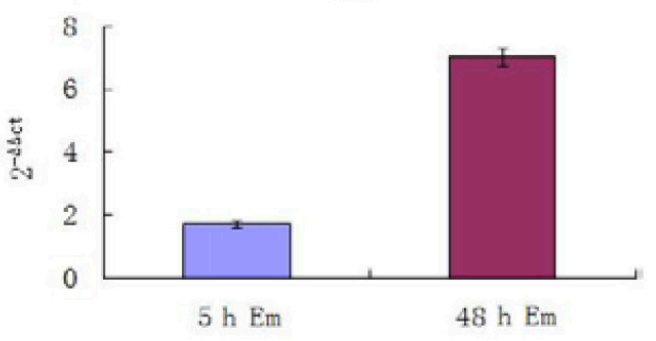

T13

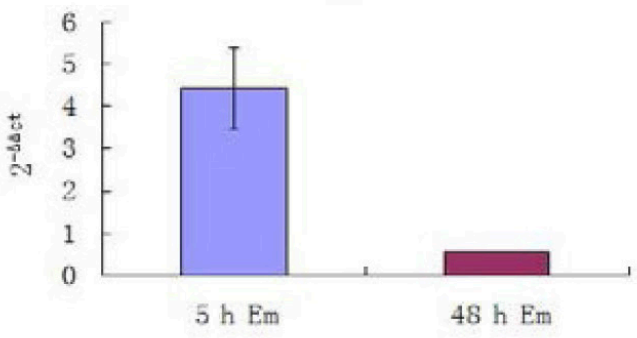

T25

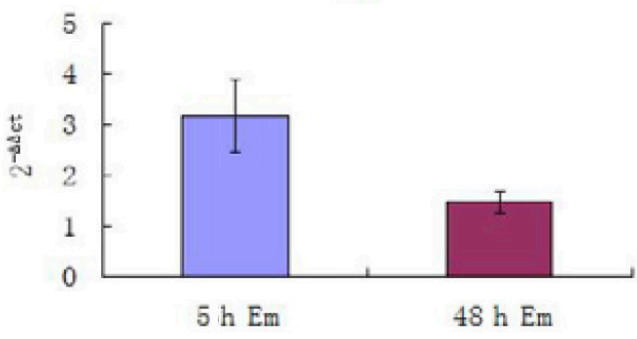

T96

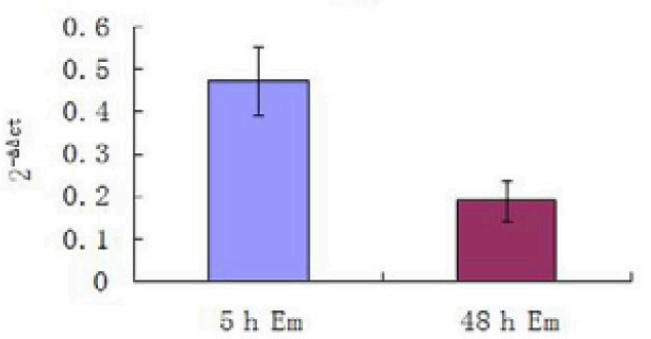

Figure 3. Transcription of eight selected black locust genes at various stages of emasculation (Em) treatment as determined by RT-qPCR. 


\section{DISCUSSION}

Of the 73 TDFs sequenced, 40 were differentially expressed between emasculated and control flowers at $5 \mathrm{~h}$, and 10 TDFs were differentially expressed at $48 \mathrm{~h}$. Moreover, $21 \mathrm{TDFs}$ were differentially expressed between emasculated and control flowers at both 5 and $48 \mathrm{~h}$. In addition, two genes were expressed at very high levels in both emasculated and control flowers at $5 \mathrm{~h}$, but exhibited no expression at $48 \mathrm{~h}$ in either. These results imply that the impact of emasculation on gene expression was greater at $5 \mathrm{~h}$ than at $48 \mathrm{~h}$.

Based on our results, the emasculation of black locust flowers has multiple effects on cellular metabolism. Aldolase activity is inhibited, thereby affecting sugar metabolism (Brinkkoetter et al., 2002). The synthesis and metabolism of long-chain fatty acids are affected, which allows flowers to become dry with subsequent negative effects on pollen growth (Trenkamp et al., 2004). The properties of epithelial cells are altered (Pruitt et al., 2000), which hinders the differentiation of pollen and stigma and inhibits epidermal cell growth in ovules (Lolle and Cheung, 1993). Membrane protein metabolism is inhibited, thus affecting the transport of membrane materials. Ribosome function is affected, resulting in the inhibition of protein synthesis. In combination, these effects of flower emasculation adversely affect substance metabolism, energy metabolism, and pollen and ovule development, and they may accelerate the flower ageing process, resulting in a reduced rate of seed set after artificial hybridization.

Not all of the responses of black locust flowers to emasculation were negative. Plants can cope with the stress caused by damage through metabolic changes. Our results showed that the expression of a tubulin-related gene increased in emasculated flowers. The levels of hyaluronic acid increased in emasculated flowers, thereby improving the water retention capacity of the cells and enhancing the maintenance of cell function. Emasculation can promote cell wall synthesis by inducing pectin synthesis, which may play a role in cellular resistance to external stress (Usadel et al., 2004).

Emasculation damage can also promote the synthesis and dephosphorylation of ATP, both of which are important for cellular energy metabolism. Emasculation increased the expression of a 28S large subunit rRNA gene, suggesting that the cells may be able to resist injury-induced stress through enhanced protein synthesis.

The expression of the Xpr1 protein, which is associated with ageing, was upregulated. The Xpr1 protein in combination with retroviruses can induce apoptosis in the human body (Yan et al., 2010), which suggests that emasculation damage may cause susceptibility to external viral infection and accelerate senescence and apoptosis. Emasculation also increased the levels of ubiquitin ligase, which promotes protein degradation.

Emasculation reduced SKP1 gene expression, which could adversely affect flower vegetative and reproductive growth, reduce the responsiveness of flowers to auxin (Lohmann et al., 2010), and impede corolla growth. Decreased SKP1 gene expression would also hinder embryo formation and late embryonic development (Liu et al., 2004). These results suggest that emasculation affects flower development and adversely affects embryo development. These effects may be important contributors to low seed set rates after artificial hybridization.

Lipoxygenase gene expression was induced by emasculation. Lipoxygenase responds to mechanical damage to cells, and it functions in insect resistance and cell ageing (Coffa et al., 2005). Emasculation also upregulates the expression of genes related to antimicrobial, antiviral and antioxidant responses in flower organs. Such changes in gene expression could increase the ability of floral organs to resist damage caused by emasculation, but they may also promote premature ageing. 
The expression of proteins involved in growth regulation and signal transduction was affected by emasculation. The expression of a cohesion complex protein was reduced, which could severely suppress cellular protein transport functions (Owen et al., 2004; Kelly et al., 2008). BT protein expression was inhibited, thereby reducing the responsiveness of flower organs to auxin. Based on the functions of TDF homologs we identified from black locust, RNA transport from the nucleus to the cytoplasm, the ability to regulate cellular osmotic pressure, epidermal growth factor receptor signal transduction, and cellular $\mathrm{pH}$ regulation would be inhibited by emasculation. These results suggest that the effects of emasculation are detrimental to normal flower development.

Black locust flowers can resist the stress of damage caused by emasculation through reinforcement of a subset of physiological functions. Emasculation promoted the expression of a plant microtubule-binding protein that plays a guiding role in the synthesis of cortical microtubules and the growth of some organs (Yao et al., 2008). The expression of the NAC transcription factor increases in Arabidopsis flowers treated with the ethylene precursor 1-aminocyclopropane-1-carboxylic acid (ACC) or abscisic acid, suggesting that NAC may be associated with flower senescence (De Oliveira et al., 2011). We showed that emasculation increased NAC transcription factor expression in black locust flowers, which indicates that emasculation likely promotes flower senescence.

Our analysis showed that emasculation influences sugar metabolism, protein metabolism, lipid metabolism, energy metabolism, substance transport, resistance signal transduction, osmotic adjustment, $\mathrm{pH}$ adjustment, photosynthesis, and other physiological process in flowers. These effects may be important contributors to the premature dropping of emasculated flowers, and they may lead to low seed set rates after artificial hybridization. We also showed that, in addition to negative impacts on flowers, emasculation could also promote some metabolic and signaling processes that enhance the capacity of flowers to resist damage caused by stress.

We sequenced 73 TDFs, including 15 of unknown function. In addition, 17 of the sequenced TDFs had no homologous entries in GenBank that were identifiable using BLASTx and BLASTn searches, indicating that the functions of many genes related to black locust flower emasculation remain unknown. If the functions of these fragments can be clarified in future studies, additional mechanisms of emasculation that affect flower development and seed set rates will be revealed.

\section{Conflicts of interest}

The authors declare no conflict of interest.

\section{ACKNOWLEDGMENTS}

Research supported by the Specialized Research Fund for the Doctoral Program of Higher Education (\#20120014130001), the International Science and Technology Cooperation Program of China (\#2014DFA31140), the National Science and Technology Support Program (\#2012BAD01B0601), the National Science Foundation of China (\#31170629), and the Beijing Municipal Science and Technology Commission Project (\#Z121100008512002). The English in this document has been checked by at least two professional editors, both native speakers of English. The data archiving has been submitted to the NCBI Database.

\section{REFERENCES}

Bachem CW, vander Hoeven RS, deBrujin SM, Vreugdenhil D, et al. (1996). Visualization of differential gene expression using 
a novel method of RNA fingerprinting based on AFLP: analysis of gene expression during potato tuber development. Plant J. 9: 745-753.

Bamunusinghe D, Liu Q, Lu X, Oler A, et al. (2013). Endogenous gammaretrovirus acquisition in Mus musculus subspecies carrying functional variants of the XPR1 virus receptor. J. Virol. 87: 9845-9855.

Bhalerao R, Keskitalo J, Sterky F, Erlandsson R, et al. (2003). Gene expression in autumn leaves. Plant Physiol. 131: 430-442.

Breyne P, Dreesen R, Cannoot B, Rombaut D, et al. (2003). Quantitative CDNA-AFLP analysis for genome-wide expression studies. Mol. Genet. Genomics 269: 173-179.

Brinkkoetter A, Shakeri-Garakani A and Lengeler JW (2002). Two class II D-tagatose-bisphosphate aldolases from enteric bacteria. Arch. Microbiol. 177: 410-419.

Coffa G, Imber AN, Maguire BC, Laxmikanthan G, et al. (2005). On the relationships of substrate orientation, hydrogen abstraction, and product stereochemistry in single and double dioxygenations by soybean lipoxygenase-1 and its Ala542Gly mutant. J. Biol. Chem. 280: 38756-38766.

De Oliveira TM, Cidade LC, Gesteira AS, Coelho Filho MA, et al. (2011). Analysis of the NAC transcription factor gene family in citrus reveals a novel member involved in multiple abiotic stress responses. Tree Genet. Genomes 7: 1123-1134.

Fukumura R, Takahashi H, Saito T, Tsutsumi $\mathrm{Y}$, et al. (2003). A sensitive transcriptome analysis method that can detect unknown transcripts. Nucleic Acids Res. 31: e94.

Guerra ME, Wunsch A, Lopez-Corrales M and Rodrigo J (2010). Flower emasculation as the cause for lack of fruit set in Japanese plum crosses. J. Am. Soc. Hort. Sci. 135: 556-562.

Harris E, Yoshida K, Cardelli J and Bush J (2001). Rab11-like GTPase associates with and regulates the structure and function of the contractile vacuole system in Dictyostelium. J. Cell Sci. 114: 3035-3045.

Heazlewood JL, Tonti-Filippini JS, Gout AM, Day DA, et al. (2004). Experimental analysis of the Arabidopsis mitochondrial proteome highlights signaling and regulatory components, provides assessment of targeting prediction programs, and indicates plant-specific mitochondrial proteins. Plant Cell 16: 241-256.

Hedhly A, Hormaza $\mathrm{JI}$ and Herrero M (2009). Flower emasculation accelerates ovule degeneration and reduces fruit set in sweet cherry. Sci. Hortic. 119: 455-457.

Keeler HL (1900). Our Native Trees and How to Identify Them. Charles Scriber's Sons, New York, 97-102.

Kelly BT, McCoy AJ, Spate K, Miller SE, et al. (2008). A structural explanation for the binding of endocytic dileucine motifs by the AP2 complex. Nature 456: 976-979.

Liu F, Ni W, Griffith ME, Huang Z, et al. (2004). The ASK1 and ASK2 genes are essential for Arabidopsis early development. Plant Cell 16: 5-20.

Lohmann D, Stacey N, Breuninger H, Jikumaru Y, et al. (2010). SLOW MOTION is required for within-plant auxin homeostasis and normal timing of lateral organ initiation at the shoot meristem in Arabidopsis. Plant Cell 22: 335-348.

Lolle SJ and Cheung AY (1993). Promiscuous germination and growth of wildtype pollen from Arabidopsis and related species on the shoot of the Arabidopsis mutant, fiddlehead. Dev. Biol. 155: 250-258.

Maldonado-Calderon MT, Sepulveda-García E and Rocha-Sosa M (2012). Characterization of novel F-box proteins in plants induced by biotic and abiotic stress. Plant Sci. 185: 208-217.

Mandadi KK, Misra A, Ren S and McKnight TD (2009). BT2, a BTB protein, mediates multiple responses to nutrients, stresses, and hormones in Arabidopsis. Plant Physiol. 150: 1930-1939.

Neuteboom LW, Ng JMY, Kuyper M, Clijdesdale OR, et al. (1999). Isolation and characterization of cDNA clones corresponding with mRNAs that accumulate during auxin-induced lateral root formation. Plant Mol. Biol. 39: 273-287.

Owen DJ, Collins BM and Evans PR (2004). Adaptors for clathrin coats: structure and function. Annu. Rev. Cell Dev. Biol. 20: 153-191.

Pruitt RE, Vielle-Calzada JP, Ploense SE, Grossniklaus U, et al. (2000). FIDDLEHEAD, a gene required to suppress epidermal cell interactions in Arabidopsis, encodes a putative lipid biosynthetic enzyme. Proc. Natl. Acad. Sci. U. S. A. 97: 1311-1316.

Reddy VS, Day IS, Thomas T and Reddy AS (2004). KIC, a novel $\mathrm{Ca}^{2+}$ binding protein with one EF-hand motif, interacts with a microtubule motor protein and regulates trichome morphogenesis. Plant Cell 16: 185-200.

Robert HS, Quint A, Brand D, Vivian-Smith A, et al. (2009). BTB AND TAZ DOMAIN scaffold proteins perform a crucial function in Arabidopsis development. Plant J. 58: 109-121.

Shi H, Ye T, Zhu JK and Chan Z (2014). Constitutive production of nitric oxide leads to enhanced drought stress resistance and extensive transcriptional reprogramming in Arabidopsis. J. Exp. Bot. 65: 4119-4131.

Smyczynski C, Roudier F, Gissot L, Vaillant E, et al. (2006). The C terminus of the immunophilin PASTICCINO1 is required for plant development and for interaction with a NAC-like transcription factor. J. Biol. Chem. 281: 25475-25484.

Subudhi PK, Nandi S, Casal C, Virmani SS, et al. (1998). Classification of rice germplasm: III. High-resolution fingerprinting of cytoplasmic genetic male-sterile (CMS) lines with AFLP. Theor. Appl. Genet. 96: 941-949.

Sun P, Yuan CQ, Dai L, Xi Y, et al. (2013). Phytohormone and assimilate profiles in emasculated flowers of the black locust 
(Robinia pseudoacacia) during development. Acta Biol. Hung. 64: 364-376.

Taglicht D, Padan E and Schuldiner S (1991). Overproduction and purification of a functional $\mathrm{Na}^{+} / \mathrm{H}^{+}$antiporter coded by nhaA (ant) from Escherichia coli. J. Biol. Chem. 266: 11289-11294.

Trenkamp S, Martin W and Tietjen K (2004). Specific and differential inhibition of very-long-chain fatty acid elongases from Arabidopsis thaliana by different herbicides. Proc. Natl. Acad. Sci. U. S. A. 101: 11903-11908.

Usadel B, Schlueter U, Molhoj M, Gipmans M, et al. (2004). Identification and characterization of a UDP-D-glucuronate 4-epimerase in Arabidopsis. FEBS Lett. 569: 327-331.

Vos P, Hogers R, Bleeker M, Reijans M, et al. (1995). AFLP: a new technique for DNA fingerprinting. Nucleic Acids Res. 23: 4407-4414.

Wagner AF, Schultz S, Bomke J, Pils T, et al. (2001). YfiD of Escherichia coli and Y06I of bacteriophage T4 as autonomous glycyl radical cofactors reconstituting the catalytic center of oxygen-fragmented pyruvate formate-lyase. Biochem. Biophys. Res. Commun. 285: 456-462.

Yan Y, Liu Q, Wollenberg K, Martin C, et al. (2010). Evolution of functional and sequence variants of the mammalian XPR1 receptor for mouse xenotropic gammaretroviruses and the human-derived retrovirus XMRV. J. Virol. 84: 11970-11980.

Yang M, Hu Y, Lodhi M, McCombie WR, et al. (1999). The Arabidopsis SKP1-LIKE1 gene is essential for male meiosis and may control homolog separation. Proc. Natl. Acad. Sci. U. S. A. 96: 11416-11421.

Yao M, Wakamatsu Y, Itoh TJ, Shoji T, et al. (2008). Arabidopsis SPIRAL2 promotes uninterrupted microtubule growth by suppressing the pause state of microtubule dynamics. J. Cell Sci. 121: 2372-2381.

Yoo AS, Bais C and Greenwald I (2004). Crosstalk between the EGFR and LIN-12/Notch pathways in C. elegans vulval development. Science 303: 663-666.

Yu J, Wang J, Lin W, Li S, et al. (2005). The genomes of Oryza sativa: a history of duplications. PLoS Biol. 3: e38.

Yuan CQ, Li Y, Lu C, Yang MS, et al. (2010). Biological effects of space-induced mutation on Robinia pseudoacacia. J. Nucl. Agric. Sci. 24: 1141-1147.

Yuan CQ, Li YF, Wang L, Zhao KQ, et al. (2013). Evidence for inbreeding depression in the tree Robinia pseudoacacia L. (Fabaceae). Genet. Mol. Res. 12: 6249-6256. 